\title{
Determinantes do custo de oportunidade dos fazendeiros em manterem a reserva legal - os casos paulista e mato-grossense
}

\author{
Determinants of farmers' opportunity cost in maintaining \\ the legal reserve - the cases of São Paulo and Mato Grosso
}

Samuel Alex Coelho Campos $^{1}$ (i) e Carlos José Caetano Bacha²

\begin{abstract}
Resumo: O objetivo deste artigo é estimar os determinantes do custo de oportunidade de os fazendeiros manterem a reserva legal dentro de sua propriedade e identificar possíveis relações espaciais existentes entre esses custos. Para tanto, o artigo toma o custo de oportunidade de manter a reserva legal por hectare para os municípios de São Paulo e Mato Grosso para os anos de 1995/96 e 2006 e utiliza modelos de econometria espacial para identificar seus principais determinantes. Os resultados encontrados indicam: (1) há presença de relações espaciais entre esses custos de oportunidade; (2) as variáveis de segunda natureza influenciam mais esses custos dos que as de primeira natureza; (3) há relações inversas entre esse custo e o tamanho da propriedade rural em São Paulo e Mato Grosso.
\end{abstract}

Palavras-chave: custo de oportunidade, reserva legal, São Paulo, Mato Grosso, econometria espacial.

\begin{abstract}
This paper aims to estimate models that explain the determination of the opportunity cost of maintaining the legal reserve inside each farm as well as to identify possible spatial relationships among these costs. In order to reach this objective, the article uses the average cost of opportunity to holding legal reserve for the municipalities of São Paulo and Mato Grosso states in the years of 199596 and 2006. By using spatial econometric models, the main results indicate: (1 $\left.1^{\text {st }}\right)$ there are spatial relationships among these opportunity costs; $\left(2^{\text {nd }}\right)$ second nature variables have more influence on these costs than the first nature variables; $\left(3^{\text {rd }}\right)$ there are different relationships between opportunity cost of maintaining legal reserve and the size of each farm for São Paulo and Mato Grosso states.
\end{abstract}

Key-words: opportunity cost, legal reserve, Sao Paulo, Mato Grosso, spatial econometrics.

Classificação JEL: C50, D22, Q18, Q23

Data de submissão: 4 de maio de 2017. Data de aceite: 18 de junho de 2018.

1. Instituto de Ciências da Sociedade e Desenvolvimento Regional (ESR), Universidade Federal Fluminense (UFF), Campos dos Goytacazes (RJ), Brasil. E-mail: s.alex.coelho@gmail.com

2. Escola Superior de Agricultura "Luiz de Queiroz" (Esalq), Universidade de São Paulo (USP), Piracicaba (SP), Brasil. E-mail: carlosbacha@usp.br 


\section{Introdução}

O Código Florestal brasileiro é um instrumento do tipo comando-controle que limita a utilização da área total dos imóveis rurais por meio, entre outros mecanismos, da instituição da Área de Preservação Permanente (APP) e da reserva legal. Essa última é uma área coberta com vegetação nativa e que deve ser conservada dentro do imóvel rural.

Ao longo do tempo, ocorreram modificações na legislação referente à reserva legal. Ela foi instituída pelo $1^{\circ}$ Código Florestal (Decreto Federal n. 23.793 de $23 / 01 / 1934$ ) que exigia que no mínimo 25\% da área total dos imóveis rurais originalmente coberta com florestas fossem mantidas como reserva florestal. O $2^{\circ}$ Código Florestal (Lei n. 4.771 de 15/09/1965 e suas alterações) ampliou a exigência da reserva legal para todos os imóveis rurais, mas diferenciou suas percentagens segundo o bioma em que o imóvel se inserisse. O $3^{\circ}$ Código Florestal (Lei n. 12.651 de 25/05 / 2012, modificada pela Lei n. 12.727 de 17/10/2012) não alterou os limites fixados para a Reserva Legal no $2^{\circ}$ Código Florestal, mas criou algumas exceções.

A manutenção da reserva legal dentro do imóvel rural implica custo de oportunidade ao produtor rural. Este custo pode corresponder ao valor de uso do solo no seu melhor uso alternativo (Richard \& Leftwich, 1970), ao valor da produção renunciada (Sipiläinen \& Huhtala, 2013) e / ou aos custos advindos da utilização de mais insumos para se adequar à menor área explorável ou pela perda da produção, tal como sugerido por Zhou et al. (2006).
O custo de oportunidade de manter a reserva legal dentro do imóvel rural é calculado na literatura por meio de duas metodologias principais, que: (i) utiliza indicadores de lucratividade e compara a rentabilidade da produção agropecuária quando a propriedade conserva a reserva legal com propriedades que não mantêm o percentual mínimo exigido em lei para a área mantida como reserva legal (Azzoni \& Isai, 1994; Bacha, 2005; Campos \& Bacha, 2013; Carneiro, 2005; Igari et al., 2009; Fasiaben et al., 2011); (ii) estima o custo de oportunidade da reserva legal por meio de uma função distância. Essa última metodologia considera a perda da produção ocasionada pela mudança na combinação necessária dos insumos para a redução do impacto ambiental (Coelli et al., 2007; Huhtala \& Marklund, 2008; Sipiläinen \& Huhtala, 2013; Zhou et al., 2006; Campos \& Bacha, 2016).

Outros estudos que trataram do cumprimento do código florestal no Brasil, mas sobre outra perspectiva em relação aos acima citados, são os trabalhos de Pires (2012) e Tourinho \& Passos (2006). O primeiro autor, Pires (2012), analisou o conhecimento dos produtores sobre a legislação florestal e o cumprimento do código florestal quando à área da Reserva Legal (RL) no município de Formosa (GO). Para tanto, questionários foram aplicados aos produtores. Dentre os resultados da pesquisa, destaca-se que os produtores conhecem a legislação florestal, mas acreditam ser injusta a imposição da manutenção da área coberta com a Reserva Legal sem receberem qualquer contrapartida. Tourinho \& Passos (2006) analisaram a viabilidade da aplicação do código florestal por meio de um estudo de caso em três propriedades na microbacia do rio Miringuava. Esses 
autores analisaram as dificuldades de adequação dos produtores rurais, bem como o custo que a manutenção da reserva legal impõe aos produtores. Alternativas para os produtores foram identificadas como a compensação da RL, dos créditos de carbono, imposto ambiental e arrendamento de áreas com florestas para a compensação da RL de outros produtores.

O impacto da eficiência técnica da produção agropecuária na Amazônia Legal sobre a probabilidade dos produtores rurais em desflorestar foi estudado por Marchand (2012). Os resultados indicaram que tanto os produtores de maior como os de menor eficiência técnica usam mais terra para a produção agropecuária do que os produtores de eficiência mediana. Segundo o citado autor, isso pode ser atribuído à distribuição desigual da posse da terra, ao livre acesso às florestas (pela dificuldade de fiscalização) e ao status de não produtivas atribuído pelos produtores às terras com matas.

O trabalho de Campos \& Bacha (2016), fazendo uso da metodologia de Zhou et al. (2006), estimou o custo de oportunidade para os fazendeiros manterem a reserva legal nos municípios de São Paulo e Mato Grosso para os anos de 1995/96 e 2006 e observou que há relações espaciais entre esses custos. No entanto, o citado trabalho não examinou os determinantes deste custo e nem utilizou modelos econométricos espaciais para evidenciar as relações espaciais entre os custos de oportunidade.

O presente trabalho tem como objetivo utilizar os dados do custo de oportunidade de manter a reserva legal dentro dos estabelecimentos agropecuários calculados por Campos \& Bacha (2016) para os estados de São Paulo e Mato Grosso - e estimar modelos que explicam os determinantes desses custos e as possíveis relações espaciais existentes ${ }^{1}$.

O presente artigo inova em relação à literatura supracitada ao identificar os determinantes do custo

1 Segundo os autores, esse custo de oportunidade permite a comparação entre os produtores, considera as diferenças de desempenho produtivo e reconhece que alguns produtores podem ter um custo de oportunidade menor do que os custos associados à perda da produção potencial advinda das ineficiências técnicas da produção. Entretanto, o custo calculado pelos autores possui como limitação a utilização do produtor médio por município e assume que qualquer desvio dos produtores em relação à fronteira de produção se deve à ineficiência. Contudo, mesmo com essas limitações, acredita-se que os resultados forneçam uma boa indicação do custo arcado pelos produtores no sentido de permitir analisar quais variáveis estariam associadas a um maior ou menor custo de oportunidade e também permitiria analisar a existência ou não de spillovers. de oportunidade em manter a reserva legal. Devido à restrição de dados existentes, a análise será feita para os anos de 1995 / 96 e 2006 e para os estados de São Paulo e Mato Grosso. Este artigo está dividido em mais quatro partes. A seguir, apresenta-se o arcabouço teórico, seguido da metodologia na seção 3 e da apresentação dos resultados na seção 4 . As conclusões do artigo são apresentadas na seção 5 , as referências bibliográficas na seção 6 e os anexos A, B, na seção 7.

\section{Arcabouço teórico}

Dentre as causas do desmatamento, Kanninen et al. (2007) citam as diretas (expansão agrícola, exploração florestal e construção de infraestrutura) e as indiretas (fatores macroeconômicos ${ }^{2}$, governamentais, dentre outros). Esses autores destacam a expansão agrícola como a principal causa do desmatamento.

Entretanto, para analisar o desmatamento, Angelsen \& Kaimowitz (1999) sugerem que sejam considerados três níveis de causas: fontes do desmatamento ou agentes; causas imediatas; e causas subjacentes. Primeiramente, devem ser identificados os agentes (pequenos agricultores, pecuaristas, madeireiros ou companhias) e sua importância para o desmatamento. As ações desses agentes são a fonte do desmatamento. Posteriormente, as causas imediatas do desmatamento, como as características internas do estabelecimento agropecuário (experiências, preferências e recursos) e externas (mercado, acesso a novas informações, infraestrutura e serviços, condições agroecológicas e instituições) devem ser analisadas. Conjuntamente, esses fatores determinam o conjunto de alternativas disponíveis e os incentivos para os produtores expandirem a produção agropecuária ou conservar a cobertura florestal. Por fim, o terceiro nível compreende as causas subjacentes, tais como as condições

\footnotetext{
2 Segundo Kanninen et al. (2007), a agropecuária expandirá para novas áreas (distantes) quanto maior for a rentabilidade dessa atividade. Essa maior rentabilidade pode ser dar via desvalorização da moeda, políticas públicas ou ações que reduzam o desempenho da economia urbana (incentivando o deslocamento das pessoas para a fronteira agrícola em busca de melhores salários), subsídios aos combustíveis fósseis (que reduziriam os custos de transporte das áreas afastadas até o mercado), entre outros fatores. Os fatores macroeconômicos também incluem a dívida externa e a política comercial.
} 
macroeconômicas nacionais e internacionais, demografia e a política agropecuária.

O modelo microeconômico de uso da terra pode ser apresentado considerando o primeiro e segundo níveis de causas do desmatamento descritos acima. Suponha que a terra seja alocada para o uso de maior geração de renda e que essa possa ter apenas dois usos (agropecuária e floresta natural, também denominada de floresta nativa), pode-se representar a renda agropecuária e da floresta natural, respectivamente, por (Angelsen, 2010):

$$
r^{a}=p^{a} y^{a}-w l^{a}-q k^{a}-v^{a} d-m^{a} r
$$

e

$$
r^{f}=\left(p^{t} y^{t}-w l^{t}-q k^{t}-v^{t} d-m^{t} r\right)+p^{l} y^{l}+p^{g} y^{g}
$$

em que $\mathrm{r}^{\mathrm{a}}$ e $\mathrm{r}^{\mathrm{f}}$ são a renda agropecuária e da floresta, respectivamente; $\mathrm{p}^{\mathrm{a}}, \mathrm{p}^{\mathrm{t}}, \mathrm{p}^{1}$ e $\mathrm{p}^{\mathrm{g}}$ são os preços de venda dos produtos agropecuários, da madeira, o valor local das amenidades florestais e o valor global das amenidades florestais ${ }^{3}$, nessa ordem; $\mathrm{y}^{\mathrm{a}}, \mathrm{y}^{\mathrm{t}}, \mathrm{y}^{\mathrm{l}}$ e $\mathrm{y}^{\mathrm{g}}$ são, respectivamente, o produto da agropecuária, da extração florestal, dos serviços (amenidades) locais e globais da floresta; w é o preço do trabalho e q é o preço do capital; $1^{\mathrm{a}}$ e $\mathrm{l}^{\mathrm{t}}$ são as quantidades necessárias de mão de obra na agropecuária e no corte da madeira, respectivamente; $k^{a}$ e $k^{t}$ são as quantidades de capital necessárias para a agropecuária e para o corte da madeira, respectivamente; $\mathrm{v}^{\mathrm{a}}$ e $\mathrm{v}^{\mathrm{t}}$ são os custos do transporte para os produtos agropecuários e florestais, respectivamente; d é a distância da fazenda ao mercado; $\mathrm{m}^{\mathrm{a}}$ e $\mathrm{m}^{\mathrm{f}}$ são os valores das multas para os produtores agropecuários, para a área desmatada e para os produtores florestais, na mesma ordem; e r representa o total desmatado da reserva legal.

O produtor irá desmatar até o ponto em que $\mathrm{r}^{\mathrm{a}}=\mathrm{r}^{\mathrm{f}}$. Assim, se o produtor não atribuir qualquer renda à floresta $\left(\mathrm{r}^{\mathrm{f}}=0\right)$, essa será substituída pela produção agrícola até que $\mathrm{r}^{\mathrm{a}}=0$. Se o produtor atribui algum benefício privado à floresta, o desmatamento será menor. Esse desmatamento será tanto menor quanto maior for o benefício que o produtor atribuir à floresta ou à medida que o produtor agropecuário for remunerado por esses benefícios.

Benefícios ou amenidades privadas: formação de solos, controle da erosão, manutenção da fertilidade do solo, proteção contra pestes agrícolas etc.; Benefícios locais: valores culturais e espirituais, proteção contra eventos climáticos, quantidade e qualidade da água etc.; Benefícios globais: proteção de recursos genéticos, mitigação das mudanças climáticas, beleza cênica, conservação da biodiversidade etc.
Entretanto, pela perspectiva social, não é desejável ${ }^{4}$ que o desmatamento seja nulo, uma vez que ele é necessário para a produção agropecuária e a consequente oferta de alimentos à sociedade (Perman et al., 2003).

A decisão de cada produtor em desmatar e alocar mais terra para a produção agropecuária é interdependente da decisão dos produtores vizinhos, segundo Robalino \& Pfaff (2012). A decisão de desmatar depende do lucro esperado da atividade agropecuária e esse depende, por sua vez, dos preços locais, que podem cair se outros produtores desmatarem e aumentarem a produção local de um dado produto. Isso reduzirá os incentivos ao desmatamento. Entretanto, a rentabilidade da agropecuária pode aumentar se os produtores que desmatarem também organizarem conjuntamente o transporte da produção agropecuária até o mercado, com ganhos de escala, segundo Robalino \& Pfaff (2012). Ademais, as condições biofísicas (clima, relevo, vegetação, declividade, qualidade do solo etc.) também influenciam a receita agropecuária e os custos de produção e, consequentemente, o benefício líquido do desmatamento.

É possível que a área desmatada seja excessiva, uma vez que os benefícios e serviços ambientais proporcionados pelas florestas naturais têm características de bens públicos (não é possível ou os custos de exclusão de alguém do consumo são proibitivamente caros). Para os bens públicos, consumidores que deles se beneficiam não pagam, enquanto os produtores não recebem para produzi-los. Essa falha de mercado leva ao sobreuso do recurso terra e ao consequente desmatamento excessivo. Para contornar esse problema podem ser utilizados alguns instrumentos de comando e controle (Perman et al., 2003), como os fixados pelo Código Florestal Brasileiro, como a reserva legal, que é o foco deste trabalho. Instrumentos do tipo comando e controle são instrumentos regulatórios que determinam e exigem parâmetros técnicos mínimos ou máximos para as atividades produtivas, sendo que seu não cumprimento acarreta, normalmente, em sanções aos infratores. Nesse sentido, o Código Florestal é um instrumento que determina, por exemplo, o padrão técnico mínimo referente à área ocupada com floresta natural destinada à reserva legal.

Esses instrumentos apresentam diversas falhas e podem acarretar em custos maiores que o mínimo possível. Uma das principais falhas se refere à desconsideração das

4 Para mais detalhes, ver o capítulo 5 de Perman et al. (2003). 
diferenças entre as firmas quanto à tecnologia de produção, acesso ao mercado e dos custos incorridos por cada uma para cumprir a legislação (Chomitz, 2004; Färe et al., 1996). Uma característica importante refere-se ao desperdício de insumos por parte do produtor (ineficiência), que pode fazer com que o produto por unidade de insumo e/ou área desmatada seja significativamente diferente entre produtores (Lee et al., 2002).

Esse custo (de oportunidade por hectare) de manter a reserva legal pode estar associado a diversas características dos estabelecimentos agropecuários e dos produtores, podendo esse custo apresentar uma relação entre produtores vizinhos. Desta forma, para analisar os determinantes do custo de oportunidade em se manter a reserva legal devem ser utilizados modelos de econometria espacial, que incorporam efeitos de relação espacial entre as variáveis nas regressões.

\section{Modelo de painel de dados com dependência espacial}

Considerando um painel balanceado, pode-se representar o modelo geral de dados em painel com dependência espacial incluindo a defasagem espacial da variável dependente e o distúrbio autorregressivo espacial, conforme Mutl \& Pfaffermayr (2011), e a defasagem espacial das variáveis independentes (ver Elhorst, 2010), tal como:

$$
\begin{aligned}
& y_{N}=\lambda W_{N} y_{N}+X_{N} \beta+W X \theta+D_{N} \gamma+u_{N} \\
& u_{N}=\rho W_{N} u_{N}+\varepsilon_{N} \\
& \varepsilon_{N}=\left(l_{T} \otimes I_{N}\right) \mu_{N}+v_{N} \\
& \text { em que } W_{N}=\left(I_{T} \otimes W_{N}\right), D_{N}=\left(\iota_{T} \otimes D_{N}\right), \\
& y_{N}=\left[\begin{array}{c}
y_{l, N} \\
\vdots \\
y_{T, N}
\end{array}\right], x_{N}=\left[\begin{array}{c}
x_{l, N} \\
\vdots \\
x_{T, N}
\end{array}\right], u_{N}=\left[\begin{array}{c}
u_{l, N} \\
\vdots \\
u_{T, N}
\end{array}\right], \varepsilon_{N}=\left[\begin{array}{c}
\varepsilon_{l, N} \\
\vdots \\
\varepsilon_{T, N}
\end{array}\right], v_{N}=\left[\begin{array}{c}
v_{l, N} \\
\vdots \\
v_{T, N}
\end{array}\right]
\end{aligned}
$$

sendo que os índices $N$ (municípios dos estados de São Paulo e Mato Grosso) e $T$ (anos analisados, 1995/96 e 2006) denotam a seção cross-sectional e a dimensão temporal do painel, respectivamente. A variável dependente é denotada por $y_{N}$ (o custo de oportunidade em se manter a reserva legal), $\boldsymbol{W}_{N} \mathbf{y}_{N}$ é a variável dependente espacialmente defasada, $\boldsymbol{W}_{N}$ são os pesos espaciais não estocásticos e $\lambda$ é o respectivo parâmetro. $\boldsymbol{X}_{N}$ é a matriz de variáveis exógenas que variam no tempo e $\beta$ é o respectivo vetor de parâmetros. WX são as variáveis exógenas espacialmente defasadas e $\theta$ é o vetor de parâmetros correspondentes. $\boldsymbol{D}_{N}$ é a matriz de observações invariantes no tempo (como a constante do modelo e variáveis para clima, altitude, bioma etc.) e $\gamma$ é o vetor de parâmetros; $\mathbf{u}_{N}$ é o termo de erro composto, $\boldsymbol{W}_{N} \mathbf{u}_{N}, \mathrm{O}$ termo de erro espacialmente defasado e $\rho$ é o parâmetro estimado para $\boldsymbol{W}_{N} \mathbf{u}_{N} ;\left(l_{T} \otimes I_{N}\right) \mu_{N}$ são os efeitos individuais não observados (fixos ou aleatórios), e $v_{N}$ é o vetor dos erros independentes e identicamente distribuídos (Millo \& Piras, 2012; Mutl \& Pfaffermayr, 2011).

O modelo retratado pela Equação 3 é denominado por Vega \& Elhorst (2015) como modelo de defasagem espacial geral (GNS). Dele, podem-se obter os modelos: (i) de defasagem espacial (SAR, Spatial Auto Regressive) fazendo $\rho=0$ e $\theta=0$; (ii) do erro autorregressivo espacial (SEM, Spatial Error Model), $\operatorname{com} \lambda=0$ e $\theta=0$; (iii) modelo autorregressivo combinado (SARAR) se $\theta=0$; (iv) modelo regressivo cruzado espacial (SLX, Spatial Lag of $X$ ) se $\rho=0$ e $\lambda=0 ;(\mathrm{v})$ Durbin espacial (SDM, Spatial Durbin Model) se $\rho=0$; e (vi) modelo regressivo espacial com erro de média móvel (SDEM, Spatial Durbin Error Model) se $\lambda=0$.

Para determinar se os efeitos individuais estão presentes no modelo, Almeida (2012) sugere utilizar o teste de Breusch \& Pagan (1979). Esse teste tem como hipótese nula a ausência de efeitos individuais $\left(H_{o}: \sigma_{\mu}^{2}=0\right)$ e segue a distribuição assintótica $\chi^{2}$ com 1 grau de liberdade. Posteriormente, para determinar qual modelo deve ser estimado (modelo com efeitos fixos ou modelo com efeitos aleatórios) será utilizado o teste de Hausman para dados espaciais em painel (Mutl \& Pfaffermayr, 2011). Por fim, foi utilizada uma matriz de vizinhança $\boldsymbol{W}_{N}$ para os k-vizinhos mais próximos, sendo a matriz $\boldsymbol{W}_{N}$ normalizada na linha. Utilizando essa matriz de vizinhança, a presença de autocorrelação espacial foi analisada por meio do teste "I" de Moran Global (Moran, 1948). O número " $\mathrm{k}$ " de vizinhos considerado foi aquele que resultou na estatística " $I$ " de maior valor significativo, conforme sugerido por Baumont (2009). Se a autocorrelação espacial estiver presente, serão estimados os modelos SAR, SEM, SARAR, SLX, SDM e SDEM, conforme sugerido por Almeida (2012), sendo o melhor modelo aquele que possuir o menor critério de informação, tendo controlada a autocorrelação espacial. 
$\mathrm{Na}$ interpretação dos efeitos marginais nos modelos SARAR, SAR, SLX, SDM e SDEM deve ser considerado o efeito feedback entre os municípios. Esse efeito advém da introdução da variável dependente defasada espacialmente $\left(\boldsymbol{W}_{N} \mathbf{y}_{N}\right)$ e das variáveis exógenas $\left(\boldsymbol{W}_{N} \mathbf{X}_{N}\right)$ na Equação 3. Isso implica que, se uma variável de um município sofre alguma variação, não apenas seu próprio custo de oportunidade deve mudar em razão dessa variação (efeito direto), mas também pelo efeito indireto advindo da interação entre os municípios.

Quanto ao alcance do efeito feedback, os modelos podem ser classificados em global e local. Nos modelos de alcance global (SARAR e SAR), o transbordamento alcança todas as regiões por meio do multiplicador espacial $^{5}$ (Lesage \& Pace, 2009). Já no modelo com transbordamento local (SLX e SDEM) se considera apenas aqueles produtores que são vizinhos de acordo com a matriz $W$, segundo Anselin (2003). O modelo SDM capta tanto o efeito feedback local como global.

Conforme Elhorst (2014) e Vega \& Elhorst (2015), a Equação 3 pode ser reescrita como

$y_{N}=\left(I_{N}-\lambda W_{N}\right)^{-1}\left[X_{N} \beta+W X_{N} \theta+D_{N} \gamma+\varepsilon_{N}\right]$

e, assim, o efeito marginal para as k-ésimas variáveis explicativas pode ser calculado. Lesage \& Pace (2009) sugerem calcular o Impacto Direto Médio, tomando a média da diagonal principal da matriz de derivadas parciais, e o Impacto Indireto Médio por meio do cálculo da média dos elementos situados fora da diagonal principal. O Efeito Total Médio é igual à média de todas as derivadas de $\mathrm{y}_{\mathrm{i}}$ em relação a $\mathrm{x}_{\mathrm{jk}}$ para todo $i$ e $j$ (esses são os produtores vizinhos).

\subsection{Variáveis usadas como determinantes do custo de oportunidade da Reserva Legal}

O presente trabalho inova no tema tratado e, portanto, não há indicações anteriores sobre as variáveis do vetor $\mathbf{X}_{\mathrm{N}}$ na Equação 3. Foram tomadas como referência as variáveis que a Nova Geografia Econômica tem considerado como de primeira e segunda natureza e a disponibilidade de dados existentes por municípios em 1995 e 2006. Contudo, a escolha das variáveis explicativas pautou-se pelas críticas de Banker \& Natarajan (2008) e McDonald (2008), de forma que essas sejam independentes das variáveis insumo utilizadas por Campos \& Bacha (2016), além de considerar o estudo de Marchand (2012).

\footnotetext{
Para mais detalhes, ver Lesage \& Pace (2009) e Elhorst (2014).
}

Assim, tem-se que a Variável Dependente é o custo de oportunidade médio por hectare (em Reais de 2006) devido à manutenção da reserva legal. Essa informação foi obtida do trabalho de Campos \& Bacha $(2016)^{6}$.

Variáveis explicativas de Primeira Natureza:

Altitude: altitude média da sede do município, em metros;

Cerrado: variável binária que recebe valor 1 para o município em que o bioma Cerrado é o predominante (ou seja, a maior proporção da área do município é coberta por esse bioma), 0 caso contrário;

Mata atlântica: variável binária que recebe valor 1 para o município em que a mata atlântica é a vegetação nativa predominante originalmente, 0 caso contrário;

Floresta Amazônica: variável binária que recebe valor 1 para o município em que a floresta Amazônica é o bioma predominante originalmente, 0 caso contrário;

Af: variável binária que recebe valor 1 se o clima predominante no município for o equatorial (Af), 0 caso contrário;

Am: variável binária que recebe valor 1 se o clima predominante no município for o de monções (Am), 0 caso contrário;

Aw: variável binária que recebe valor 1 se o clima predominante no município for o tropical de savana, com estação seca no inverno (Aw), 0 caso contrário;

As: variável binária que recebe valor 1 se o clima predominante no município for o tropical de Savana, com estação seca no verão (As), 0 caso contrário;

Cwa: variável binária que recebe valor 1 se o clima predominante no município for o subtropical

6 O trabalho de Campos \& Bacha (2016) originalmente considera um produtor representativo médio. O custo por hectare foi obtido multiplicando aquele valor pelo número de produtores e, em seguida, esse resultado foi dividido pela área dos estabelecimentos em cada município. Esses autores utilizaram a metodologia proposta por Zhou et al. (2006) que, por meio da Análise Envoltória de Dados, permite calcular o custo da regulação sobre uma atividade produtiva. Campos \& Bacha (2016) utilizaram como variável de produto a receita agropecuária e como variáveis de insumo: (i) a área total destinada à produção agropecuária; (ii) mão de obra; (iii) efetivo bovinos; (iv) despesas com defensivos e (v) número de tratores. Para mais detalhes, ver Campos \& Bacha (2016). 
úmido, com inverno seco e verão quente (Cwa), 0 caso contrário;

Cwb: variável binária que recebe valor 1 se o clima predominante no município for o subtropical úmido, com inverno seco e verão temperado (Cwb), 0 caso contrário;

Cfa: variável binária que recebe valor 1 se o clima predominante no município for o oceânico, com verão quente (Cfa), 0 caso contrário;

Cfb: variável binária que recebe valor 1 se o clima predominante no município for o verão temperado (Cfb), 0 caso contrário;

Mato Grosso: variável binária que recebe valor 1 se o município está localizado no estado de Mato Grosso, 0 caso contrário;

Fronteira.MT: variável binária que recebe valor 1 se o município está localizado no estado de Mato Grosso e faz fronteira com outro estado, 0 caso contrário; e

Fronteira.SP: variável binária que recebe valor 1 se o município está localizado no estado de São Paulo e faz fronteira com outro estado, 0 caso contrário;

Variáveis Explicativas de Segunda Natureza (sendo AE a área total dos estabelecimentos em hectares e NE, o número total dos estabelecimentos)

Estabelecimentos: Proporção da área dos municípios ocupada com estabelecimentos agropecuários;

Assistência: Percentual dos estabelecimentos agropecuários que receberam assistência técnica;

Adubação: Valor dispendido pelos estabelecimentos agropecuários com adubos e corretivos do solo, em Reais de 2006;

Plantio em nível: Percentual de estabelecimentos agropecuários que utilizaram o plantio em nível;

Terraços: Porcentual de estabelecimentos que utilizaram terraços;

Eletricidade: Percentual dos estabelecimentos agropecuários que informaram utilizar energia elétrica;

Irrigação: Percentual da área dos estabelecimentos agropecuários irrigada;

Área: área média dos estabelecimentos agropecuários;

Área2: área média dos estabelecimentos agropecuários ao quadrado, em hectares;
Tratores: Número de tratores, em unidades / área dos estabelecimentos (AE), utilizada como proxy para o capital dos estabelecimentos agropecuários;

Financiamento: Valor dos financiamentos recebidos pelos estabelecimentos agropecuários em Reais de dezembro de 2006/Número dos estabelecimentos (NE);

Investimento: Valor dos investimentos realizados pelos estabelecimentos agropecuários em Reais de dezembro de 2006 / NE;

Demografia: Número de pessoas residentes por quilometro quadrado;

Cursos ciências agrárias: Número de cursos na área de ciências agrárias em universidades ${ }^{7}$;

Assentamento: variável binária que recebe o valor 1 se há assentamentos no município, 0 caso contrário;

IDH-M: Indicador utilizado como proxy para o desenvolvimento dos municípios;

Agências bancárias: número de agências bancárias (públicas e privadas) no município;

Permanentes: variável binária que recebe valor 1 se a maior proporção da área do município está ocupada com culturas permanentes, 0 caso contrário;

Temporária: variável binária que recebe valor 1 se a maior proporção da área do município está ocupada com culturas temporárias, 0 caso contrário;

Pastagem natural: variável binária que recebe valor 1 se a maior proporção da área do município está ocupada com pastagens naturais, 0 caso contrário;

Pastagem plantada: variável binária que recebe valor 1 se a maior proporção da área do município está ocupada com pastagens plantadas, 0 caso contrário;

Foram considerados os cursos de Administração em Agronegócios, Administração Rural, Agronomia, Superior em Tecnologia Ambiental, Superior de Tecnologia em Agricultura Sustentável, Superior de Tecnologia em Agronegócios, Superior de Tecnologia em Gestão de Agronegócios, Superior de Tecnologia em Gestão de Agronegócios e Mercado de Commodities, Superior de Tecnologia em Processos Sucroalcooleiro, Superior de Tecnologia em Produção Sucroalcooleira, Superior de Tecnologia em Zootecnia, Engenharia Agrícola, Engenharia Agrícola e Ambiental, Engenharia Agronômica, Engenharia de Produção Agroindustrial, Engenharia Florestal, Gestão Ambiental, Medicina Veterinária e Zootecnia. 
Mata natural: variável binária que recebe valor 1 se a maior proporção da área do município está ocupada com matas naturais, 0 caso contrário;

Mata plantada: variável binária que recebe valor 1 se a maior proporção da área do município está ocupada com matas plantadas, 0 caso contrário;

Inaproveitável: variável binária que recebe valor 1 se a maior proporção da área do município corresponde à áreas não aproveitáveis para a agropecuária, 0 caso contrário.

Ademais, algumas variáveis interativas foram adicionadas buscando captar diferenças na relação entre as variáveis explicativas e o custo de oportunidade entre os estados. Foram adicionadas as variáveis: Adubação. Mato Grosso (obtida pela multiplicação entre adubação e a variável binária para Mato Grosso), Financiamento. Mato Grosso, Investimento.Mato Grosso, Demografia. Mato Grosso, Area.Mato Grosso e Área².Mato Grosso. Adotou-se para cálculo dessas cinco últimas variáveis o mesmo procedimento adotado para a primeira citada no parágrafo.

As variáveis de boas práticas agrícolas ("Plantio em nível" e "Terraços") foram adicionadas como forma de capturar a conservação ambiental. A forma quadrática da variável área foi incluída visando captar possíveis efeitos não lineares. A variável "Financiamento" foi inserida buscando captar o efeito do acesso ao crédito e a capacidade de adoção de novas tecnologias, modernização dos equipamentos e substituição de equipamentos depreciados/sucateados sobre o custo de oportunidade. Considerando a possibilidade de uma parte do valor financiado poder não ser investida e ser utilizada para outros objetivos, foi adicionada a variável "Investimentos" para capturar o efeito do que é efetivamente investido.

A variável "assentamentos" busca captar o efeito sobre a forma de ocupação e projetos de colonização (importante para o estado de Mato Grosso). Conforme apontado por Bonjour et al. (2008), os assentamentos apresentariam um padrão de ocupação dos lotes que apresentaria baixa produtividade, baseado na retirada da mata, plantio de arroz e braquiária, e pecuária. Segundo esses autores, esse processo poderia reduzir a produtividade das pastagens e o custo de oportunidade de manter as áreas com Reserva Legal pode ser menor. A presença de assentamentos rurais de reforma agrária pode estar associada também ao aumento do custo de oportunidade por meio da insegurança e o receio de ocupações de áreas não efetivamente incorporadas no processo produtivo - ocupadas com a Reserva Legal. As informações sobre a presença de assentamentos em cada município dos estados analisados foram obtidas em Brasil (2014).

O Índice de Desenvolvimento Humano Municipal (IDHM) foi obtido do Programa das Nações Unidas para o Desenvolvimento (2015) para os anos de 1991 e 2000 e utilizados como proxy para os anos de 1996/96 e 2006, respectivamente. Assume-se que o aumento da renda e do desenvolvimento leve à valorização das amenidades proporcionadas pelas matas e florestas e reduza o custo de oportunidade de se conservar a reserva legal.

As variáveis binárias para bioma (Cerrado, Floresta Atlântica e Floresta Amazônica) e clima (Af, Am, Aw, As, Cwa, Cwb, Cfa e Cfb) permitem analisar a diferença do custo de oportunidade advinda das condições edafoclimáticas dos municípios em virtude de suas diferenças na produtividade e das tecnologias de produção que utilizam em face dessas condições. Ressalta-se que os biomas são aproximações das condições edafoclimáticas e buscam tão somente controlar efeitos não observados e não são o objetivo principal da análise. As variáveis de fronteira (Fronteira.MT e Fronteira.SP) foram incorporadas à análise como forma de contornar o efeito da borda ou problema da fronteira ${ }^{8}$, conforme Anselin (1988) e Griffith (1985). As variáveis binárias ${ }^{9}$ para área ocupada por atividades agropecuárias buscam captar a relação entre a ocupação da área e o custo de oportunidade.

Os mapas georreferenciados dos municípios de São Paulo e Mato Grosso para o cálculo da matriz de vizinhança foram obtidos junto ao IBGE. A densidade populacional foi calculada utilizando o número de habitantes por município da Contagem Populacional de 1996 (Instituto Brasileiro de Geografia e Estatística, 2014) e 2007 (Instituto Brasileiro de Geografia e Estatística, 2009) e dados do site Cidades@ (área da unidade municipal), ambos disponibilizados pelo Instituto Brasileiro de Geografia e Estatística. O número de agências bancárias

\footnotetext{
8 Segundo Anselin (1988), o problema da fronteira surge quando o valor de uma variável de uma dada unidade espacial incluída na amostra (observada) depende dos valores de outra (s) unidade espacial não incluída na amostra (não observada).

$9 \quad$ Helfand \& Levine (2004) utilizaram variáveis semelhantes ao analisar os determinantes da eficiência técnica no Centro-Oeste.
} 
em cada município foi obtido junto ao Banco Central do Brasil (2014) e o número de cursos de ciências agrárias foi retirado dos microdados do Censo da Educação Superior junto ao Instituto Nacional de Estudos e Pesquisas Educacionais Anísio Teixeira (2013).

Os municípios emancipados foram aglutinados aos municípios "originais" conforme a metodologia proposta por Paiva $(2007,2008)$. Esse procedimento foi necessário por terem ocorrido emancipações e desmembrações de municípios ao longo do tempo. Desta forma, os estados de São Paulo e Mato Grosso apresentarão, respectivamente, 625 e 117 municípios em cada ano analisado, ou seja, o mesmo número de municípios no período base de 1995.

Para a criação e análise das matrizes de vizinhos, estimação da estatística do I de Moran, estimação dos efeitos diretos, indiretos e totais; estimação dos testes de hipoteses múltiplas, teste de presença de efeitos individuais e estimação do modelo espacial em painel e do teste de Hausman espacial, foi utilizado o programa estatístico R (R Core Team, 2015).

\section{Resultados e discussão}

O trabalho de Campos \& Bacha (2016) já sugeriu, por meio da Análise Exploratória de Dados Espaciais, a possível existência de relações espaciais dos custos de oportunidade dos produtores em manter a reserva legal nos municípios de São Paulo e de Mato Grosso. Neste item, apresentam-se os resultados dos procedimentos estatísticos que provam a existência dessas relações espaciais e das estimativas econométricas que dimensionam os possíveis determinantes desses custos de oportunidade.

\subsection{Análise exploratória dos dados espaciais}

Inicialmente, os dados foram organizados de forma a assegurar um painel balanceado, exigência da metodologia utilizada para estimar o modelo de regressão espacial com dados em painel. Assim, o município que apresentou algum valor faltante para menos uma variável em pelo menos um ano analisado foi retirado da análise. Os dados totalizaram, então, 1.258 observações, sendo 89 municípios mato-grossenses e 540 municípios paulistas em cada ano.

Posteriormente, a estatística I de Moran indicou que há relação espacial na distribuição entre os municípios do custo de oportunidade dos seus produtores em manterem a reserva legal. Ela foi calculada para os anos de 1995 / 96 e 2006 considerando de cinco a 15 vizinhos. Essa estatística permite, também, determinar o número ideal de vizinhos na construção da matriz de pesos espaciais. A matriz de vizinhança com $\mathrm{k}$ vizinhos que resultar no maior valor significativo da estatística I indica o número $\mathrm{k}$ de vizinhos a ser considerado. O maior valor significativo foi aquele com cinco vizinhos, sendo o valor estimado de 0,151 e 0,179 para o I de Moran para 1995/96 e 2006, respectivamente.

Os resultados para a estatística $I$ foram positivos e significativos. Isso indica uma relação de similaridade (alto-alto ou baixo-baixo), de forma que o custo de oportunidade de produtores mais próximos é mais similar do que se o custo estivesse distribuído aleatoriamente pelo espaço. Nesse sentido, produtores com elevado (baixo) custo de oportunidade tendem a estar agrupados dentro dos estados analisados.

Para analisar as diferenças na estrutura da autocorrelação espacial local, foram construídos os mapas de clusters dos Indicadores Locais de Associação Espacial (Local Indicator of Spatial Association - Lisa) para Mato Grosso (Figura 1) e São Paulo (Figura 2). Conforme Plant (2012), a estrutura espacial local pode ser diferente da autocorrelação espacial global ${ }^{10}$, sendo que a última é caracterizada por apenas uma estatística (o I de Moran).

No estado de Mato Grosso, há o aumento no número de agrupamentos do tipo alto-alto entre 1995 e 2006. Em 1995, a maior parte dos municípios foi enquadrada como baixo-baixo. Em 2006, o número de municípios com elevado custo de oportunidade no uso da reserva legal aumentou, principalmente no centro do estado, nas regiões de Sinop e Sorriso, de elevada produção de soja. Esse aumento pode ser explicado pela expansão da produção de soja no estado de Mato Grosso.

Em São Paulo, observa-se o aumento dos municípios do grupo baixo-baixo nas porções noroeste e sudoeste do estado e uma redução dos municípios nos agrupamentos baixo-baixo no sudeste e do alto-alto no centro-norte do

10 Destaca-se que os indicadores Lisa têm a propriedade de que, tomando a soma do seu valor para todas as observações, obtém-se o seu valor global. Nessa análise, o valor global da autocorrelação espacial foi analisado pelo I de Moran. Nesse sentido, a maior predominância de algum tipo de agrupamento espacial não necessariamente indica a natureza da autocorrelação global, haja visto que essa depende da magnitude das estatísticas Lisa e não do número de observações em cada agrupamento, propriamente. 
Figura 1. Agrupamentos Lisa para o custo de oportunidade, Mato Grosso, anos de 1995 e 2006

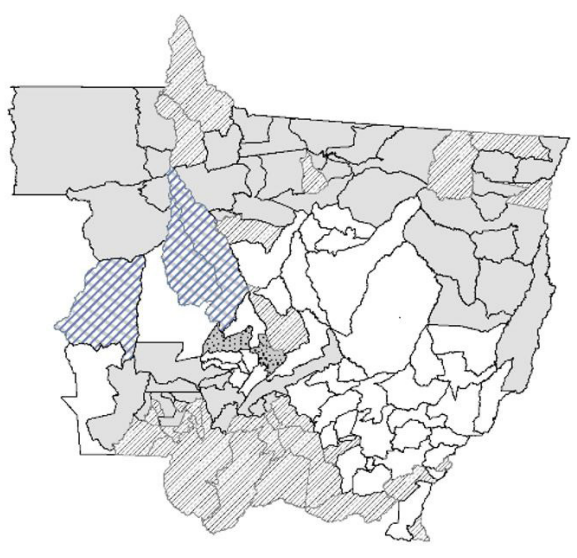

Mato Grosso - 1995

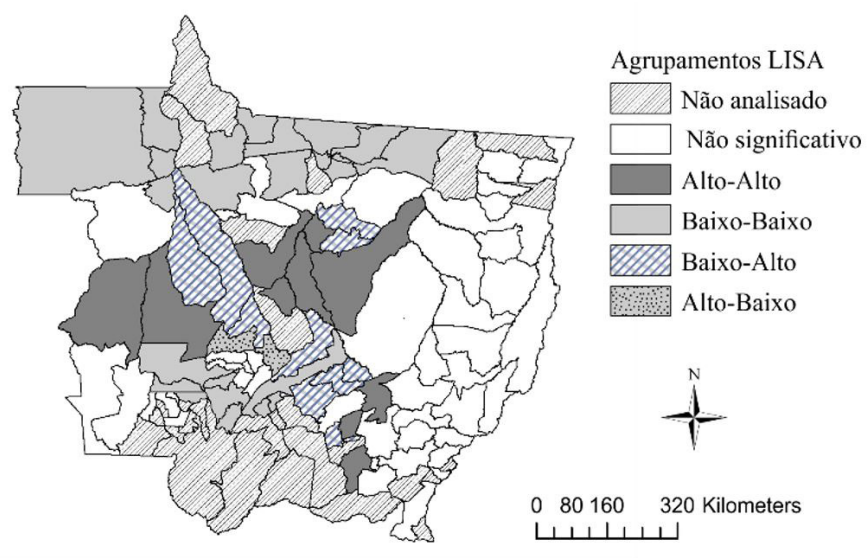

Mato Grosso - 2006

Fonte: Resultado da pesquisa.

Figura 2. Agrupamentos Lisa para o custo de oportunidade, São Paulo, anos de 1995 e 2006

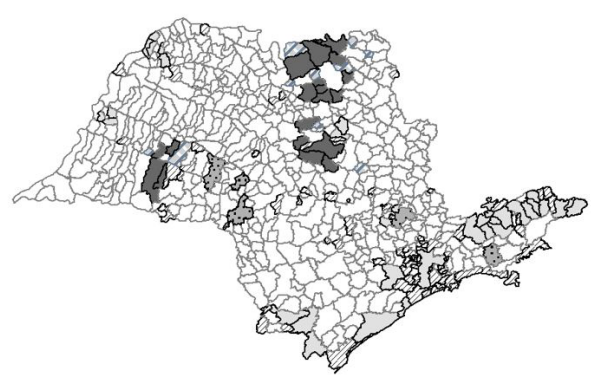

São Paulo - 1995

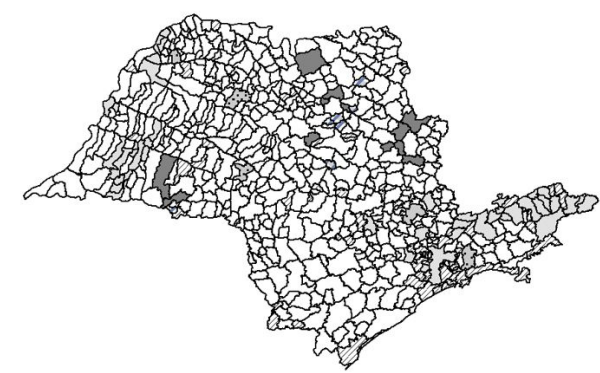

São Paulo - 2006
Agrupamentos LISA

Não analisado

Não significativo

Alto-Alto

Baixo-Baixo

VIA Baixo - Alto

Alto - Baixo
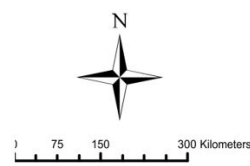

Fonte: Resultado da pesquisa.

estado, entre 1995 e 2006. Os municípios que não foram enquadrados em agrupamentos e estão identificadas como "não significativo" são aqueles em que o valor do custo de oportunidade de manter a reserva legal não é diferente, em termos estatísticos, da média de todos os municípios ao seu redor, conforme Almeida (2012).

Esses resultados indicam que há uma dinâmica diferente nos estados analisados quanto à distribuição dos custos de oportunidade por municípios e revelam a existência de agrupamentos espaciais locais. Produtores de elevado (baixo) custo estavam próximos de produtores de alto (baixo) custo de oportunidade - relação de similaridade - bem como produtores de elevado (baixo) custo estariam próximos de produtores de baixo (elevado) custo - relação de dissimilaridade.

\subsection{Especificação e estimação das regressões espaciais}

O teste de Breusch e Pagan indicou a necessidade de incorporar os efeitos espaciais na estimação dos determinantes do custo de oportunidade em se manter a reserva legal. O valor para a estatística $\chi^{2}$ foi igual a 26,83 , significativo estatisticamente ao nível de $1 \%$. Pelo teste de Hausman, proposto por Mutl \& Pfaffermayr (2011), os efeitos individuais não observados são correlacionados às variáveis explicativas, com estatística $\chi_{19}^{2}$ g.l. igual a 83,37 , estatisticamente significativo ao nível de $1 \%$. Assim, o modelo de efeitos aleatórios seria viesado e, portanto, o modelo de efeitos fixos deve ser utilizado.

O teste I de Moran - para testar a presença de autocorrelação espacial dos resíduos do modelo de efeitos 
fixos - indicou que há autocorrelação espacial nesse modelo, sendo $I=-0,088$, e significativo estatisticamente ao nível de $1 \%$. Esse valor estimado indica que há dissimilaridade, e, portanto, a análise dos determinantes do custo de oportunidade deve considerar que o mesmo não se distribui aleatoriamente no espaço.

Foram, então, estimados os modelos SAR, SEM, SARAR, SLX, SDM e SDEM, e aplicado o teste I de Moran nos resíduos de cada modelo (Tabela 1 ).

Os resultados indicam que os modelos SARAR e SEM não são adequados, uma vez que não foram capazes de controlar a autocorrelação espacial ao nível de significância de $5 \%$. Subsequentemente, foram calculados os critérios de informação (Tabela 2) para os modelos SAR, SDEM, SDM e SLX para auxiliar na escolha do modelo.

Os critérios de informação foram inclusivos, pois o AIC indica que o modelo SLX é o mais adequado e o critério BIC indica o modelo SAR. Entretanto, considerando que o nível de significância do teste de I de Moran do modelo SLX foi superior ao SAR, optou-se pelo primeiro modelo para a análise dos determinantes do custo de oportunidade da área da reserva legal (Tabela 3).

O modelo SLX incorpora as variáveis exógenas espacialmente defasadas como variáveis explicativas.

Tabela 1. Estatística I de Moran para os resíduos das regressões espaciais em painel do custo de oportunidade, anos de 1995 e 2006

\begin{tabular}{ccc}
\hline Modelo & Estatística $I$ & P valor \\
\hline SARAR & $-7,67$ & 0,00 \\
SEM & $-5,00$ & 0,00 \\
SAR & $-1,93$ & 0,05 \\
SDEM & $-0,06$ & 0,94 \\
SDM & $-0,24$ & 0,81 \\
SLX & $-0,11$ & 0,91 \\
\hline
\end{tabular}

Fonte: Resultados da pesquisa.

Nota: AIC - Critério de Informação de Akaike; BIC - Critério de Informação Bayesiano.

Tabela 2. Critérios de informação Akaike e Bayesiano para os modelos de regressão espacial

\begin{tabular}{ccc}
\hline Modelo & AIC & BIC \\
\hline SAR & $17.463,89$ & $17.582,05$ \\
SDEM & $17.468,57$ & $17.776,81$ \\
SDM & $17.468,44$ & $17.776,67$ \\
SLX & $17.458,82$ & $17.761,92$ \\
\hline
\end{tabular}

Fonte: Resultados da pesquisa.

Nota: AIC - Critério de Informação de Akaike; BIC - Critério de Informação Bayesiano.
Nesse modelo, o valor da variável dependente de um agente é depende das características dos estabelecimentos agropecuários vizinhos. Esse resultado vai ao encontro da argumentação de Robalino \& Pfaff (2012), ou seja, o custo de oportunidade de um município depende não somente de suas características, mas também da dos seus vizinhos. Essa relação é esperada, uma vez que municípios vizinhos tendem a apresentar eficiência técnica, culturas agropecuárias e comportamento semelhantes quanto ao tratamento dado à Reserva Legal - desmatando ou não a mesma.

Como o modelo foi estimado por efeitos fixos, o efeito das variáveis que eram constantes ao longo do tempo foi controlado, devendo ser removidas da estimação. Buscando um melhor ajustamento do modelo ${ }^{11}$, as variáveis para plantio em nível, eletricidade, terraços, idhm e irrigação ${ }^{12}$ foram retiradas do modelo. Essas variáveis não foram estatisticamente significativas tanto individualmente (teste $\mathrm{t}$ ) como conjuntamente (teste $\mathrm{F}$ ) ao nível de significância de $10 \%$. A variável binária para o estado de São Paulo foi omitida na estimação. Assim, todas as variáveis interativas podem ser comparadas diretamente à respectiva variável não interativa, analisando se há diferença na relação entre o efeito marginal dessa variável entre Mato Grosso e São Paulo.

As estimativas do modelo SLX, conforme Vega \& Elhorst (2015), permitem obter os efeitos diretos e indiretos (Tabela 3). Os efeitos diretos de uma variável " $\mathrm{k}$ " de um produtor ' $\mathrm{i}$ " sobre o custo de oportunidade dele mesmo são as respectivas estimativas dos parâmetros $\beta_{k}$ (Equação 3). Os efeitos indiretos, o efeito de uma variável " $k$ " de um produtor " $\mathrm{i}$ " sobre o custo de oportunidade de um produtor " $j$ ", vizinho a " $i$ ", foram

11 Algumas variáveis, apesar de não serem estatisticamente significativas, foram mantidas na estimação de forma a facilitar a interpretação de outras variáveis. Este foi o caso das variáveis Área média.Mato Grosso e Investimento. Mato Grosso.

12 A escolha das variáveis a serem retiradas ou incluídas no modelo também considerou a sensibilidade da variação dos parâmetros estimados à sua retirada do modelo de regressão. Conforme Wooldridge (2006), a inclusão de variáveis irrelevantes ao modelo não cria viés, podendo implicar em multicolinearidade e maior variância aos parâmetros estimados, enquanto a exclusão de variáveis relevantes comumente gera viés às estimativas. Assim, a retirada de variáveis não relevantes não deve apresentar mudança perceptível nos parâmetros estimados, podendo reduzir, entretanto, a variância estimada de todos os parâmetros e aumentar a significância das estimativas. 
Tabela 3. Estimativas para os determinantes do custo de oportunidade, efeitos fixos para São Paulo e Mato Grosso, anos de 1995/96 e 2006

\begin{tabular}{|c|c|c|c|c|}
\hline Variável & Estimativa & Desvio Padrão & Estatística t & P valor \\
\hline \multicolumn{5}{|l|}{ Efeito Direto } \\
\hline Proporção & $15,97^{* * *}$ & 5,77 & 2,77 & 0,01 \\
\hline Adubação (Proporção de estabelecimentos) & $-2,8 \mathrm{E}-04^{* *}$ & 1,3E-04 & $-2,09$ & 0,04 \\
\hline Abubação* dummy para Mato Grosso & $-2,2 \mathrm{E}-04$ & $4,5 \mathrm{E}-04$ & $-0,49$ & 0,63 \\
\hline Área média & $-4,19^{* * * *}$ & 0,42 & $-9,96$ & 0,00 \\
\hline$(\text { Área média })^{2}$ & $2,1 \mathrm{E}-3^{* * *}$ & 0,00 & 8,44 & 0,00 \\
\hline Área média * dummy para Mato Grosso & $4,37^{* * *}$ & 0,48 & 9,19 & 0,00 \\
\hline (Área média) $^{2 *}$ dummy para Mato Grosso & $-2,2 \mathrm{E}-03^{* * *}$ & $2,6 \mathrm{E}-04$ & $-8,36$ & 0,00 \\
\hline Financiamento, em Reais & $-6,6 \mathrm{E}-05$ & $8,4 \mathrm{E}-05$ & $-0,79$ & 0,43 \\
\hline Financiamento * dummy para Mato Grosso & $-0,01^{* *}$ & $2,5 \mathrm{E}-03$ & $-2,14$ & 0,03 \\
\hline Investimento, em Reais & $4,0 \mathrm{E}-04^{* * *}$ & $1,3 \mathrm{E}-04$ & 3,14 & 0,00 \\
\hline Agências bancárias, em unidades & $-1,83^{* *}$ & 0,76 & $-2,40$ & 0,02 \\
\hline Permanentes (dummy) & $-201,07^{* * *}$ & 75,06 & $-2,68$ & 0,01 \\
\hline Temporária (dummy) & $-122,42^{*}$ & 69,23 & $-1,77$ & 0,08 \\
\hline Pastagem natural (dummy) & $-209,94^{* * *}$ & 70,38 & $-2,98$ & 0,00 \\
\hline Pastagem plantada (dummy) & $-148,34^{* *}$ & 65,07 & $-2,28$ & 0,02 \\
\hline Matas plantadas (dummy) & $-456,44^{* * *}$ & 166,24 & $-2,75$ & 0,01 \\
\hline Inaproveitável (dummy) & $-287,48^{* * *}$ & 82,53 & $-3,48$ & 0,00 \\
\hline Outliers & $655,35^{* * *}$ & 67,96 & 9,64 & 0,00 \\
\hline Fronteira.SP & 3,01 & 53,48 & 0,06 & 0,96 \\
\hline Fronteira.MT & 51,21 & 124,85 & 0,41 & 0,68 \\
\hline \multicolumn{5}{|l|}{ Efeito Indireto } \\
\hline W* (Proporção) & $-28,74^{* *}$ & 11,95 & $-2,4052$ & 0,02 \\
\hline W* (Área média) & $3,13^{* * *}$ & 0,90 & 3,4851 & 0,00 \\
\hline $\mathrm{W} *\left(^{\text {Área média })^{2}}\right.$ & $-8,5 \mathrm{E}-04$ & $5,3 \mathrm{E}-04$ & $-1,6145$ & 0,11 \\
\hline W* (Área média * dummy para MT) & $-2,65^{* * *}$ & 0,91 & $-2,8998$ & 0,00 \\
\hline $\mathrm{W}^{*}\left((\text { Área média })^{2 *}\right.$ dummy para MT)) & $8,0 \mathrm{E}-04$ & $5,4 \mathrm{E}-04$ & 1,4792 & 0,14 \\
\hline $\mathrm{W}^{*}$ (Trator) & $-184,33^{* * *}$ & 54,82 & $-3,3622$ & 0,00 \\
\hline $\mathrm{W}^{*}$ (Financiamento) & $-5,4 \mathrm{E}-05$ & $1,6 \mathrm{E}-04$ & $-0,3322$ & 0,74 \\
\hline $\mathrm{W}^{*}$ (Financiamento * dummy para MT) & $0,01^{* *}$ & 0,01 & 2,1416 & 0,03 \\
\hline $\mathrm{W}^{*}($ Demografia $)$ & $-0,25^{* * *}$ & 0,03 & $-7,5272$ & 0,00 \\
\hline $\mathrm{W}^{*}$ (Outliers) & $-325,71^{* * *}$ & 108,24 & $-3,0091$ & 0,00 \\
\hline
\end{tabular}

Fonte: Resultados da pesquisa. Nota: ${ }^{*}, * *$ e ${ }^{* * *}$ indicam significativo a 10\%,5\% e 1\%, respectivamente. A variável Outliers recebe valor 1 se o município foi identificado como ponto de alavancagem ou outliers, 0 caso contrário, conforme sugerido por Bivand et al. (2008). Os outliers e pontos de alavancagem foram identificados por meio das estatísticas hii - o valor da diagonal da matriz $\mathrm{H}=\mathrm{X}\left(\mathrm{X}^{\prime} \mathrm{X}\right)-1 \mathrm{X}^{\prime}$, razão de covariância, dfbetas, dffits, e distância de Cook. O município foi considerado outlier ou ponto de alavancagem se pelo menos um desses testes indicou que aquela observação era um outlier ou ponto de alavancagem. Para mais detalhes, ver Plant (2012, p. 566-571) e R Core Team (2015).

obtidos diretamente por meio do respectivo coeficiente $\theta_{k}$ (Equação 3).

A interpretação e análise dos resultados estão focadas nos efeitos diretos e indiretos das variáveis estatisticamente significativas $^{13}$ (Tabela 3). Algumas estimativas, mesmo

13 As estimativas para todos os parâmetros estão apresentadas em anexo na Tabela B1. não sendo estatisticamente significativas, serão analisadas, dada a sua importância.

O coeficiente associado à proporção da área dos municípios ocupada com estabelecimentos apresentou significância estatística tanto para o efeito direto como para o efeito indireto, mas com sinais opostos. O coeficiente do efeito direto (de 15,97$)$ indica que o aumento na área 
ocupada com estabelecimentos aumenta o custo de oportunidade em $\mathrm{R} \$ 15,97$ por hectare a cada um ponto percentual de acréscimo na proporção da área ocupada pelos estabelecimentos agropecuários. Isso pode ser explicado pela diminuição da área total disponível para a agropecuária em cada município e da valorização da área já utilizada para a agropecuária. Contudo, o efeito indireto indica que o aumento da proporção da área ocupada com estabelecimentos em um dado município reduz o custo de oportunidade dos municípios vizinhos em $\mathrm{R} \$ 28,74$ por hectare. Os produtores agropecuários individualmente não são capazes de influenciar os preços dos seus produtos. Entretanto, o aumento da produção nos municípios vizinhos pode reduzir os preços dos na região. Isso reduziria a rentabilidade e o custo de oportunidade de manter a área coberta com a reserva legal. Essa relação também é apontada por Robalino \& Pfaff (2012).

O coeficiente do efeito direto associado à área apresentou um comportamento quadrático conforme esperado. O efeito marginal direto estimado para a área ao quadrado foi positivo para o estado de São Paulo e negativo para o estado de Mato Grosso. A relação entre o custo de oportunidade e a área média dos estabelecimentos é descrita por curvas de formatos diferentes (Figura 1) ${ }^{14}$ para cada estado.

A equação que associa o custo de oportunidade de manter a reserva legal e a área, tomando o efeito direto para São Paulo é descrita por 2,1E-03*(Área média) ${ }^{2}-$ 4,19*(Área média), que decresce a taxas crescentes. Para Mato Grosso, tem-se a equação -6,0E-05* (Área média) ${ }^{2}$ $+0,18^{*}$ (Área média), que cresce a taxas decrescentes na primeira parte da parábola. A equação representa uma parábola em forma de U para São Paulo e em forma de U invertido para Mato Grosso. Entretanto, como pode ser observado na Figura 3, a maioria das observações em São Paulo está concentrada na parte decrescente da curva, enquanto que, para Mato Grosso, as observações estão concentradas na porção crescente ${ }^{15}$. Nesse sentido, em ambos os estados os produtores maiores arcam com menor custo de oportunidade de manter a RL

14 A Figura 3 representa a parábola obtida quando o custo de oportunidade é estimado tomando apenas a área dos estabelecimentos por meio dos parâmetros do modelo. Isso explica os valores negativos nos eixos verticais. Essa figura busca ilustrar a relação entre o custo de oportunidade em se manter a reserva legal e a área média dos estabelecimentos.

15 As estatísticas descritivas das variáveis para Mato Grosso e São Paulo por ano analisado estão disponíveis na Tabela A1 e Tabela A2, respectivamente.
Figura 3. Relação estimada entre a área média dos estabelecimentos, em hectares, e o custo de oportunidade por hectare estimado em função da área,

São Paulo e Mato Grosso, anos de 1996/96 e 2006

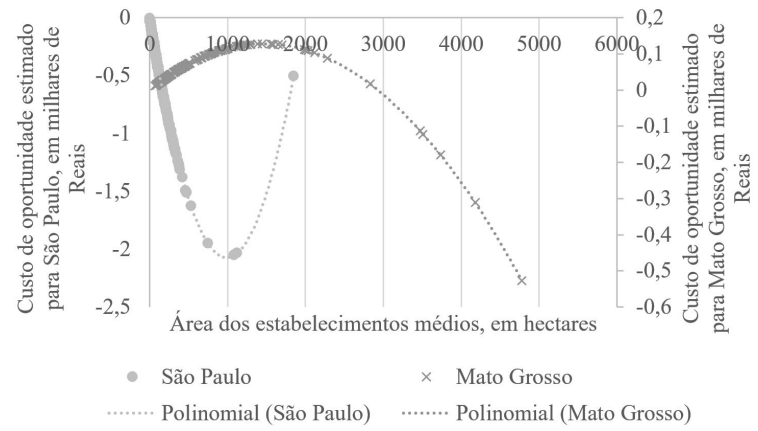

Fonte: Resultados da pesquisa.

por hectare de área total. Apesar de o efeito indireto apresentar comportamento contrário, o efeito direto domina a relação por ser maior em valor absoluto do que o efeito indireto.

Portanto, em Mato Grosso os menores produtores arcam com um custo de oportunidade da reserva legal proporcionalmente superior aos produtores que dispõem de uma área maior (Figura 3). Isso poderia ser explicado pela principal atividade produtiva, em que os menores produtores podem se dedicar à criação de gado de corte. No estado de São Paulo, os maiores produtores arcam com custo de oportunidade menor, tanto em termos absolutos como proporcionais, do que os menores produtores. Importante destacar que esse efeito se refere à média por hectare para os produtores. Nesse sentido, os pequenos produtores do cinturão verde de São Paulo podem apresentar um custo de oportunidade maior, proporcionalmente.

Esses resultados para Mato Grosso e São Paulo ${ }^{16}$ são corroborados pelos argumentos de Tourinho \& Passos (2006) para o Paraná. Eles afirmaram que, na pequena propriedade, a redução da área explorável advinda da restrição da reserva legal pode comprometer a sustentabilidade econômica. Resultado semelhante foi obtida por Pires (2012), que analisou as áreas de Reserva Legal (RL) no município de Formosa (GO), em 2011, e concluiu que a RL é mais onerosa, proporcionalmente, para os pequenos produtores. Marchand (2012) também concluiu que os pequenos produtores convertem mais

16 Excetuando-se o município de Alumínio em 1995, que apresentou área média dos estabelecimentos de 1.848,88 ha. e custo de oportunidade estimado (Figura 3) de R $\$ 13,54$. 
terras para a produção agropecuária do que os maiores produtores. Portanto, os pequenos produtores seriam mais dependentes da área da Reserva Legal para a produção agropecuária. Conforme Angelsen \& Kaimowitz (2001) e Marchand (2012), pequenos produtores estão sujeitos a maiores restrições, como de capital, do que os maiores produtores e, por isso, tendem a utilizar de forma mais abundante o fator mais barato, a terra.

A variável de financiamento foi significativa apenas para Mato Grosso (Financiamento.MT). Contudo, os efeitos direto e indireto para a variável Financiamento.MT se anulam. A variável para investimento foi estatisticamente significativa, não havendo diferença estatística entre São Paulo e Mato Grosso (Investimento.MT não foi significativa). O coeficiente dessa variável, apesar de pequeno, apresenta significado econômico. Por exemplo, em 2006, o custo médio de oportunidade em manter a reserva legal por hectare no estado de São Paulo foi de $\mathrm{R} \$ 377,50$ e o valor dos investimentos foi de $\mathrm{R} \$ 22.425,08$. Tomando o valor médio do investimento, obtém-se redução em São Paulo de R\$ 8,90 (4,0E-04*22.425,08) ou 2,4\% no custo de oportunidade. No estado de Mato Grosso, em 2006, a redução no curto de oportunidade alcança $\mathrm{R} \$ 13,50$ por hectare $((4,0 \mathrm{E}-04 * 34 \cdot 022,20)$. O investimento médio para Mato Grosso em 2006 foi de $R \$ 34.022,20$ e o custo de oportunidade médio foi de R\$ 0,04. Assim, os efeitos marginais (diretos) do investimento sobre o custo de oportunidade são maiores em Mato Grosso do que em São Paulo. Portanto, a produção agropecuária no primeiro estado é mais sensível a variações no investimento.

As estimativas indicaram que a existência de agências bancárias estaria associada à redução do custo de oportunidade no próprio município em $\mathrm{R} \$ 1,83$ a cada agência. Essa redução pode ser explicada pelo fato de o crédito rural poder ser condicionado à manutenção da área coberta com Reserva Legal. Conforme Guimarães (2015), os bancos reconhecem que as atividades produtivas financiadas possuem impacto ambiental. Assim, os agentes podem condicionar o financiamento à adoção de procedimentos de redução do impacto ambiental e a presença de agência bancária no próprio município pode facilitar a tomada de crédito visando a aquisição de tecnologia intensiva no uso da terra e, com isso, haverá menor custo de oportunidade de manter a reserva legal. Entretanto, o efeito indireto não foi estatisticamente significativo, o que indica que a variação no número de agências bancárias em um município não influencia o custo de oportunidade dos municípios vizinhos. Esses resultados indicam que os produtores se relacionam em agências do seu próprio município e, também, a importância da existência de agências bancárias em todos os municípios.

Dentre as variáveis binárias para o principal uso da área dos estabelecimentos, todas as variáveis foram estatisticamente significativas (para o efeito direto). Os efeitos indiretos não foram estatisticamente significativos ao nível de significância de $10 \%$. A variável para matas naturais foi omitida e, portanto, é a base de comparação. Nesse sentido, o coeficiente negativo para a variável "Permanentes", por exemplo, indica que o custo de oportunidade em manter a reserva legal por hectare é menor em R \$201,07 quando comparado ao custo por hectare dos estabelecimentos agropecuários, que têm a maior parte da área ocupada com matas (naturais). Comportamento semelhante foi observado para as variáveis "Temporária", "Pastagem plantada", "Pastagem natural" e "Inaproveitáveis". Esses resultados indicam, assim, que os produtores serão incentivados a converter a área ocupada com matas e florestas para a produção agropecuária, haja visto que a área ocupada por matas não propicia, de forma geral, nenhum retorno econômico (na percepção dos produtores agropecuários).

Destaca-se que as variáveis "Trator" e "Demografia" tiveram apenas os efeitos indiretos estatisticamente significativos. Nesse sentido, o número de tratores pode ser relacionado ao crescimento da produção agropecuária, à redução da rentabilidade por hectare e, consequentemente, à redução do custo de oportunidade. Interpretação semelhante pode ser feita para a variável demografia, em que um aumento da população dos municípios vizinhos aumentaria o mercado e a oferta dos produtos agropecuários e, assim reduziria o preço dos produtos agropecuários e do custo de oportunidade.

\section{Conclusões}

O objetivo deste artigo foi analisar os determinantes do custo de oportunidade por hectare dos fazendeiros em cumprirem com a obrigação de manutenção da reserva legal dentro de suas propriedades. A análise baseou-se em dados dos municípios de São Paulo e Mato Grosso. 
Os resultados indicaram que o custo de oportunidade de um município em manter a reserva legal de um produtor depende e é determinado conjuntamente com o custo de oportunidade de seus vizinhos. Destaca-se que os produtores de menor área total apresentaram os maiores custos de oportunidade por hectare. Portanto, eles seriam mais sensíveis à perda da área produtiva representada pela restrição do código florestal.

Os resultados indicaram, por meio das variáveis binárias, que as áreas ocupadas com matas naturais apresentam custo de oportunidade superior às áreas ocupadas com atividades produtivas agropecuárias (e até mesmo em relação às áreas inaproveitáveis para a agropecuária). Nesse sentido, a área ocupada com matas naturais teria um custo de oportunidade por hectare superior em $\mathrm{R} \$ 456,44$ por hectare em relação à área ocupada com matas plantadas (de exploração econômica). Por fim, destaca-se que o aumento da área ocupada com estabelecimentos agropecuários no próprio município aumenta o custo de oportunidade das áreas que permanecem ocupadas com matas em virtude da valorização da terra.

Dentre as limitações desse trabalho destacam-se: (i) a análise por hectare médio de cada município; (ii) a variável "desmatamento" considerou apenas o desmatamento da área de reserva legal e (iii) supôs-se que todos os estabelecimentos agropecuários deveriam ter reserva legal. Não obstante essas limitações, os resultados obtidos neste artigo indicam que os produtores agropecuários arcam sozinhos com o custo de oportunidade de manter a reserva legal dentro de seus imóveis. Assim, os produtores devem ser compensados economicamente, de forma a manterem a área de Reserva Legal, o que gera benefícios para toda a sociedade. Esse incentivo poderia se dar, por exemplo, via redução das taxas de juros do crédito rural - o que o atual Código Florestal permite.

A importância das matas para a manutenção da quantidade e qualidade da água é particularmente importante no estado de São Paulo, uma vez que a região Metropolitana de São Paulo (RMSP) enfrentou forte crise de abastecimento de água em 2014 devido à falta de chuvas. As matas nativas contribuem para a redução da erosão do solo por reduzirem o impacto das gotas de chuva sobre o solo, apresentando, também, um obstáculo mecânico à enxurrada (Vanzela et al., 2010). As matas ciliares, em específico, oferecem proteção contra a erosão ao diminuírem a velocidade do fluxo da enxurrada, favorecendo a infiltração da água, o que diminui o transporte de sedimentos até os corpos de água (Machado et al., 2003). Ademais, convém destacar que o Novo Código Florestal de 2012 permite que a APP seja contabilizada como área de reserva legal para alguns estabelecimentos agropecuários, ou seja, a reserva legal também pode compreender matas ciliares em alguns estabelecimentos agropecuários. Contudo, ao permitir a incorporação das APPs nesse cômputo, a área total de matas nativas nos estabelecimentos agropecuários é reduzida, o que, por sua vez, reduz os seus serviços ecossistêmicos, como a manutenção da quantidade e qualidade das águas, por exemplo.

Nesse sentido, ações na bacia hidrográfica para a manutenção da quantidade e qualidade da água são importantes, e elas poderiam ser alcançadas por meio de programas de Pagamento por Serviços Ambientais (Herrero, 2014) que encorajasse o produtor a manter áreas ocupadas com matas dentro do estabelecimento agropecuário. Assim, o Novo Código Florestal (Lei n. 12.651/2012), ao criar o Programa de Apoio e Incentivo à Conservação do Meio Ambiente, permite que o governo federal incentive a conservação das matas (entre outras legislações). Os resultados aqui apresentados podem ser utilizados na definição de programas de pagamentos por serviços ambientais que incentivem tanto a conservação quanto a produção agropecuária.

Conforme os resultados indicaram, é importante considerar que cada produtor pode ter um custo diferente de oportunidade em manter a RL, e um pagamento igual para todos os produtores implicará desperdício de recursos. Ademais, os resultados também indicaram a necessidade de considerar a dependência espacial e os transbordamentos espaciais existentes entre os produtores, que podem potencializar ou atenuar os efeitos totais esperados das ações de incentivo à conservação das áreas ocupadas com matas.

Por fim, destaca-se que o Novo Código Florestal permite, em alguns casos, incluir as APPs no cômputo da reserva legal da propriedade, em alguns estabelecimentos que atendem a alguns requisitos. Assim, essa modificação legal pode alterar o custo de oportunidade estimado no presente artigo. Sugere-se que próximos estudos sobre o tema levem este aspecto em consideração, que não pode ser aqui tratado dada a indisponibilidade atual de dados pós 2012. 


\section{Referências}

Almeida, E. (2012). Econometria espacial (498 p.). Campinas: Alínea.

Angelsen, A. (2010). Policies for reduced deforestation and their impact on agricultural production. Proceedings of the National Academy of Sciences of the United States of America, 107(46), 19639-19644.

Angelsen, A., \& Kaimowitz, D. (1999). Rethinking the causes of deforestation: Lessons from economic models. The World Bank Research Observer, 14(1), 73-98.

Angelsen, A., \& Kaimowitz, D. (2001). Introduction: the role of agricultural technologies in tropical deforestation. In A. Angelsen \& D. Kaimowitz (Eds.), Agricultural technologies and tropical deforestation (Chap. 1, pp. 1-18). Jakarta: Center for International Forestry Research/ CABI Publishing.

Anselin, L. (1988). Spatial econometrics: methods and models (284 p.). Dordrecht: Kluwer Acdemic Publishers.

Anselin, L. (2003). Spatial externalities, spatial multipliers, and spatial econometrics. International Regional Science Review, 26(2), 153-166.

Azzoni, C. R., \& Isai, J. Y. (1994). Estimating the costs of environmental protection in Brazil. Ecological Economics, 11(2), 127-133.

Bacha, C. J. C. (2005). Eficácia da política de reserva legal no Brasil. Teoria e Evidência Econômica, 13(25), 9-27.

Banco Central do Brasil - BCB. (2014). Relação de agências e postos bancários (transferência de arquivos). Recuperado em 6 de agosto de 2014, de http:/ / www.bcb.gov. $\mathrm{br} /$ ?RELAGPAB

Banker, R. D., \& Natarajan, R. (2008). Evaluating contextual variables affecting productivity using Data Envelopment Analysis. Operations Research, 56(1), 48-58.

Baumont, C. (2009). Spatial effects of urban public policies on housing values. Papers in Regional Science, 88(2), 301-327.

Bivand, R., Pebesma, E. J., \& Gómez-Rubio, V. (2008). Applied spatial data analysis with $R$ (374 p.). New York: Spinger.

Bonjour, S. C. M., Figueiredo, A. M. R., \& Marta, J. M. C. (2008). A pecuária de corte no estado de Mato Grosso. In Anais do Congresso da Sociedade Brasileira de Economia, Administração e Sociologia Rural (pp. 1-21). Cuiabá: SOBER.

Brasil. Ministério da Agricultura, Pecuária e Abastecimento. (2014). Estatísticas e dados básicos de economia agrícola (54 p.). Brasília.

Breusch, T. S., \& Pagan, A. R. (1979). A simple test for heteroscedasticity and random coefficient variation. Econometrica, 47(5), 1287-1294.
Campos, S. A. C., \& Bacha, C. J. C. (2013). O custo privado da reserva legal. Revista de Política Agrícola, 22(2), 85-104.

Campos, S. A. C., \& Bacha, C. J. C. (2016). O custo privado da reserva legal para os produtores agropecuários de São Paulo e Mato Grosso nos anos de 1995 e 2006. Revista de Economia e Sociologia Rural, 54(1), 71-88.

Carneiro, S. L. (2005). Estudo prospectivo da implantação da reserva legal em propriedades rurais familiares representativas de sistemas de produção de grãos na região de Londrina - Estado do Paraná (Dissertação de mestrado). Universidades Estaduais de Londrina e Maringá, Londrina.

Chomitz, K. M. (2004). Transferable development rights and forest protection: an exploratory analysis. International Regional Science Review, 27(3), 348-373.

Coelli, T. J., Lauwers, L., \& Huylenbroeck, G. (2007). Environmental efficiency measurement and the materials balance condition. Journal of Productivity Analysis, 28(12), 3-12.

Elhorst, J. P. (2010). Spatial panel data models. In M. M. Fischer \& A. Getis (Eds.), Handbook of applied spatial analysis: software tools, methods and applications (Chap. C2, pp. 377-407). Heidelberg: Springer-Verlag.

Elhorst, J. P. (2014). Spatial econometrics from cross-sectional data to spatial panels (119 p.). Berlin: Springer-Verlag

Färe, R., Grosskopf, S., \& Tyteca, D. (1996). An activity analysis model of the environmental performance of firms: application to fossil-fuel-fired electric utilities. Ecological Economics, 18(2), 161-175.

Fasiaben, M. D. C. R., Romeiro, A. R., Peres, F. C., \& Maia, A. G. (2011). Impacto econômico da reserva legal sobre diferentes tipos de unidades de produção agropecuária. Revista de Economia e Sociologia Rural, 49, 1051-1096.

Griffith, D. A. (1985). An evaluation of correction techniques for boundary effects in spatial statistical analysis: contemporary methods. Geographical Analysis, 17(1), 81-88.

Guimarães, G.L.E. (2015). Gerenciamento do risco socioambiental nas instituições financeiras bancárias no Brasil (Dissertação de mestrado). Universidade de Brasília, Brasília.

Helfand, S. M., \& Levine, E. S. (2004). Farm size and the determinants of productive efficiency in the Brazilian Center-West. Agricultural Economics, 31(2-3), 241-249.

Herrero, T. (2014). Saídas possíveis. Página 22, (84), 38-41.

Huhtala, A., \& Marklund, P.-O. (2008). Stringency of environmental targets in animal agriculture: shedding light on policy with shadow prices. European Review of Agriculture Economics, 35(2), 193-217.

Igari, A., Tambosi, L., \& Pivello, V. (2009). Agribusiness opportunity costs and environmental legal protection: investigating trade-off on hotspot preservation in the 
state of São Paulo, Brazil. Environmental Management, 44(2), 346-355.

Instituto Brasileiro de Geografia e Estatística - IBGE. (2009). Censo Agropecuário 2006: Brasil, Grandes Regiões e Unidades da Federação (pp. 1-777). Rio de Janeiro: IBGE.

Instituto Brasileiro de Geografia e Estatística - IBGE. (2014). Censo Agropecuário 1996/96/96. Rio de Janeiro: IBGE. Recuperado em 27 de fevereiro de 2014, de http: / / www.sidra.ibge.gov.br/bda/pesquisas / ca/default1996. asp? $\mathrm{z}=\mathrm{p} \& \mathrm{o}=2 \& \mathrm{i}=\mathrm{P}$

Instituto Nacional de Estudos e Pesquisas Educacionais Anísio Teixeira - INEP. (2013). Microdados Censo da Educação Superior. Recuperado em 15 de julho de 2014, de http: / / portal.inep.gov.br/basica-levantamentos-acessar

Kanninen, M., Murdiyarso, D., Seymour, F., Angelsen, A., Wunder, S., \& German, L. (2007). Do trees grow on money? The implications of deforestation research for policies to promote REDD (61 p.). Bogor: Center for International Forestry Research.

Lee, J.-D., Park, J.-B., \& Kim, T.-Y. (2002). Estimation of the shadow prices of pollutants with production/environment inefficiency taken into account: a nonparametric directional distance function approach. Journal of Environmental Management, 64(4), 365-375.

Lesage, J. P., \& Pace, R. K. (2009). Introduction to spatial econometrics (373 p.). Boca Raton: CRC Press Taylor \& Francis Group.

Machado, R. E., Vettorazzi, C. A., \& Xavier, A. C. (2003). Simulação de cenários alternativos de uso da terra em uma microbacia utilizando técnicas de modelagem e geoprocessamento. Revista Brasileira de Ciência do Solo, 27(4), 727-733.

Marchand, S. (2012). The relationship between technical efficiency in agriculture and deforestation in the Brazilian Amazon. Ecological Economics, 77, 166-175.

McDonald, J. (2008). Using least squares and tobit in second stage DEA efficiency analyses. European Journal of Operational Research, 197, 792-798.

Millo, G., \& Piras, G. (2012). splm: spatial panel data models in R. Journal of Statistical Software, 47(1), 1-38.

Moran, P. A. P. (1948). The interpretation of statistical maps. Journal of the Royal Statistical Society. Series B. Methodological, 10(2), 243-251.

Mutl, J., \& Pfaffermayr, M. (2011). The Hausman test in a Cliff and Ord panel model. The Econometrics Journal, 14(1), 48-76.

Paiva, C. A. (2007). Uma alternativa à metodologia das AMCs. Porto Alegre: FEE. Recuperado em 18 de janeiro de 2014, de http:/ / www.fee.tche.br/rs-em-mapas-edados/index.html

Paiva, C. A. (2008). Evolução das desigualdades territoriais no Rio Grande do Sul. Santa Cruz do Sul: Edunisc.

Perman, R., Ma, Y., Common, M., Maddison, D., \& McGilvray, J. (2003). Natural resource and environmental economics (728 p.). Harlow: Pearson.

Pires, C. S. J. (2012). As alterações do Código Florestal brasileiro e as conseqüencias sobre as áreas de Reservas Legais do Município de Formosa-GO (Dissertação de mestrado). Faculdade de Tecnologia, Universidade de Brasília, Brasília.

Plant, R. E. (2012). Spatial data analysis in ecology and agriculture using $R$ (617 p.). New York: CRC Press.

Programa das Nações Unidas para o Desenvolvimento - PNUD. (2015). Ranking IDHM municípios. Recuperado em 31 de janeiro de 2015, de http: / / www.pnud.org.br / atlas / ranking/Ranking-IDHM-Municipios-2000.aspx.

R Core Team. (2015). R: a language and environment for statistical computing. Vienna: R Foundation for Statistical Computing. Recuperado em 1 de abril de 2015, de http: / / www.R-project.org

Richard, H. L., \& Leftwich, R. H. (1970). Introduction to microeconomics. New York: New York Holt, Rinehart and Winston.

Robalino, J. A., \& Pfaff, A. (2012). Contagious development: neighbor interactions in deforestation. Journal of Development Economics, 97(2), 427-436.

Sipiläinen, T., \& Huhtala, A. (2013). Opportunity costs of providing crop diversity in organic and conventional farming: would targeted environmental policies make economic sense? European Review of Agriculture Economics, 40(3), 441-462.

Tourinho, L. A. M., \& Passos, E. (2006). O código florestal na pequena propriedade rural: um estudo de caso em três propriedades na microbacia do rio Miringuava. Revista RAEGA, 12, 221-233.

Vanzela, L. S., Hernandez, F. B. T., \& Franco, R. A. M. (2010). Influência do uso e ocupação do solo nos recursos hídricos do Córrego Três Barras, Marinópolis. Revista Brasileira de Engenharia Agrícola e Ambiental, 14(1), 55-64.

Vega, S. H., \& Elhorst, J. P. (2015). The SLX model. Journal of Regional Science, 55(3), 339-363.

Wooldridge, J. M. (2006). Introductory econometrics: a modern approach (890 p.). Mason: Thomson Higher Education.

Zhou, P., Ang, B. W., \& Poh, K. L. (2006). Slacks-based efficiency measures for modeling environmental performance. Ecological Economics, 60(1), 111-118. 
ANEXO A. Estatísticas descritivas.

Tabela A1. Estatísticas descritivas para as variáveis determinantes do custo de oportunidade para o estado de Mato Grosso, de 1995 e 2006

\begin{tabular}{|c|c|c|c|c|}
\hline \multirow{2}{*}{ Variáveis } & \multicolumn{2}{|c|}{1995} & \multicolumn{2}{|c|}{2006} \\
\hline & Média & Desvio Padrão & Média & Desvio Padrão \\
\hline Custo de Oportunidade (em R $\$$ / ha) & 32,532 & 38,282 & 0,048 & 0,063 \\
\hline Assistência (Proporção de estabelecimentos) & 0,3384 & 0,252 & 0,292 & 0,156 \\
\hline Adubação (em R\$) & 16509,17 & 44557,7 & 52407,53 & 195884,9 \\
\hline Plantio em Nível (Proporção de estabelecimentos) & 0,083 & 0,130 & 0,131 & 0,151 \\
\hline Terraços (Proporção de estabelecimentos) & 0,051 & 0,121 & 0,032 & 0,071 \\
\hline Irrigação (Percentual da área irrigada) & 0,001 & 0,006 & 0,003 & 0,005 \\
\hline Área média (em hectares) & 836,32 & 838,012 & 549,401 & 591,358 \\
\hline$(\text { Área média })^{2}$ & 1393815 & 3328657 & 647618,1 & 2079981 \\
\hline Trator, em unidades & 0,593 & 0,710 & 0,529 & 0,638 \\
\hline Financiamento, em Reais & 10550,09 & 22987,46 & 12911,68 & 11761,98 \\
\hline Investimento, em Reais & 18267,96 & 17571,57 & 34022,2 & 121378,9 \\
\hline Demografia, pessoas $/ \mathrm{km}^{2}$ & 6,345 & 22,906 & 5,230 & 7,775 \\
\hline Agências bancárias, em unidades & 1,483 & 1,188 & 1,483 & 1,686 \\
\hline N. de cursos em Ciências Agrárias & 0 & 0 & 0,224 & 0,734 \\
\hline Assentamento (dummy) & 0,471 & 0,502 & 0,921 & 0,270 \\
\hline Altitude & 332,780 & 124,572 & 332,780 & 124,572 \\
\hline Floresta Amazônica (dummy) & 0,516 & 0,502 & 0,516 & 0,502 \\
\hline Cerrado (dummy) & 0,471 & 0,502 & 0,471 & 0,502 \\
\hline Am (dummy) & 0,0112 & 0,106 & 0,011 & 0,106 \\
\hline $\mathrm{Cfb}$ (dummy) & 0 & 0 & 0 & 0 \\
\hline Cwa (dummy) & 0 & 0 & 0 & 0 \\
\hline $\operatorname{Af}(d u m m y)$ & 0 & 0 & 0 & 0 \\
\hline Aw (dummy) & 0,988 & 0,106 & 0,988 & 0,106 \\
\hline Cfa (dummy) & 0 & 0 & 0 & 0 \\
\hline IDHM & 0,391 & 0,065 & 0,546 & 0,051 \\
\hline Permanentes (dummy) & 0 & 0 & 0 & 0 \\
\hline Temporária (dummy) & 0,382 & 0,488 & 0,426 & 0,497 \\
\hline Pastagem natural (dummy) & 0,056 & 0,231 & 0,022 & 0,149 \\
\hline Pastagem plantada (dummy) & 0,483 & 0,502 & 0,606 & 0,491 \\
\hline Matas naturais (dummy) & 0,426 & 0,497 & 0,269 & 0,446 \\
\hline Matas plantadas (dummy) & 0 & 0 & 0 & 0 \\
\hline Inaproveitável (dummy) & 0 & 0 & 0 & 0 \\
\hline
\end{tabular}

Fonte: Resultados da pesquisa. 
306 Determinantes do custo de oportunidade dos fazendeiros em manterem a reserva legal - os casos paulista e mato-grossense

Tabela A2. Estatísticas descritivas para as variáveis determinantes do custo de oportunidade para o estado de São Paulo, de 1995 e 2006

\begin{tabular}{|c|c|c|c|c|}
\hline \multirow{2}{*}{ Variáveis } & \multicolumn{2}{|c|}{1995} & \multicolumn{2}{|c|}{2006} \\
\hline & Média & Desvio Padrão & Média & Desvio Padrão \\
\hline Custo de Oportunidade (em R $\$$ / ha) & 419,804 & 621,901 & 377,487 & 402,329 \\
\hline Assistência (Proporção de estabelecimentos) & 0,512 & 0,234 & 0,489 & 0,184 \\
\hline Adubação (em R\$) & 10641,63 & 19661 & 22668,49 & 128399,1 \\
\hline Plantio em Nível (Proporção de estabelecimentos) & 0,494 & 0,253 & 0,473 & 0,210 \\
\hline Terraços (Proporção de estabelecimentos) & 0,113 & 0,143 & 0,119 & 0,127 \\
\hline Irrigação (Percentual da área irrigada) & 0,032 & 0,068 & 0,0445 & 0,072 \\
\hline Área média (em hectares) & 98,459 & 101,881 & 93,994 & 97,979 \\
\hline$(\text { Área média })^{2}$ & 20054,8 & 148382,9 & 18416,95 & 80957,96 \\
\hline Trator, em unidades & 0,899 & 0,783 & 0,766 & 0,561 \\
\hline Financiamento, em Reais & 13821,65 & 58585,8 & 21811,7 & 175008 \\
\hline Investimento, em Reais & 15836,05 & 22973,39 & 22425,08 & 126676,6 \\
\hline Demografia, pessoas $/ \mathrm{km}^{2}$ & 249,584 & 1061,33 & 232,343 & 989,950 \\
\hline Agências bancárias, em unidades & 3,288 & 28,305 & 5,6 & 57,805 \\
\hline № de cursos em Ciências Agrárias & 0,037 & 0,189 & 0,15 & 0,714 \\
\hline Assentamento (dummy) & 0 & 0 & 0,113 & 0,317 \\
\hline Altitude & 556,958 & 171,038 & 556,959 & 171,0384 \\
\hline Floresta Amazônica (dummy) & 0,716 & 0,451 & 0,717 & 0,451 \\
\hline Cerrado (dummy) & 0,283 & 0,451 & 0,283 & 0,451 \\
\hline Am (dummy) & 0 & 0 & 0 & 0 \\
\hline $\mathrm{Cfb}($ dummy) & 0,033 & 0,180 & 0,033 & 0,180 \\
\hline Cwa (dummy) & 0,014 & 0,120 & 0,015 & 0,121 \\
\hline $\operatorname{Af}(d u m m y)$ & 0,005 & 0,074 & 0,006 & 0,074 \\
\hline Aw (dummy) & 0,511 & 0,500 & 0,511 & 0,500 \\
\hline Cfa (dummy) & 0,435 & 0,496 & 0,435 & 0,496 \\
\hline IDHM & 0,496 & 0,058 & 0,645 & 0,047 \\
\hline Permanentes (dummy) & 0,209 & 0,407 & 0,226 & 0,419 \\
\hline Temporária (dummy) & 0,518 & 0,500 & 0,515 & 0,500 \\
\hline Pastagem natural (dummy) & 0,107 & 0,301 & 0,157 & 0,364 \\
\hline Pastagem plantada (dummy) & 0,505 & 0,500 & 0,272 & 0,446 \\
\hline Matas naturais (dummy) & 0,057 & 0,233 & 0,059 & 0,236 \\
\hline Matas plantadas (dummy) & 0,009 & 0,096 & 0 & 0 \\
\hline Inaproveitável (dummy) & 0 & 0 & 0,087 & 0,282 \\
\hline
\end{tabular}

Fonte: Resultados da pesquisa. 
ANEXO B. Estimativas dos determinantes do custo de oportunidade com todas as variáveis para o modelo SLX com efeitos fixos.

Tabela B1. Estimativas completas para os determinantes do custo de oportunidade, SLX com efeitos fixos para São Paulo e Mato Grosso, anos de 1995/96 e 2006

\begin{tabular}{|c|c|c|c|c|}
\hline Variável & Estimativa & Desvio Padrão & Estatística $\mathbf{t}$ & P valor \\
\hline Proporção & $15,97^{* * *}$ & 5,77 & 2,77 & 0,01 \\
\hline Adubação (Proporção de estabelecimentos) & $-2,8 \mathrm{E}-04^{* *}$ & 1,3E-04 & $-2,09$ & 0,04 \\
\hline Abubação * dummy para Mato Grosso & $-2,2 \mathrm{E}-04$ & $4,5 \mathrm{E}-04$ & $-0,49$ & 0,63 \\
\hline Área média & $-4,19^{* * * *}$ & 0,42 & $-9,96$ & 0,00 \\
\hline$(\text { Área média })^{2}$ & $0,00^{* * *}$ & 0,00 & 8,44 & 0,00 \\
\hline Área média * dummy para Mato Grosso & $4,37^{* * *}$ & 0,48 & 9,19 & 0,00 \\
\hline$(\text { Área média })^{2 *}$ dummy para Mato Grosso & $-2,2 \mathrm{E}-03^{* * *}$ & 2,6E-04 & $-8,36$ & 0,00 \\
\hline Trator, em unidades & 19,20 & 26,46 & 0,73 & 0,47 \\
\hline Financiamento, em Reais & $-6,6 \mathrm{E}-05$ & $8,4 \mathrm{E}-05$ & $-0,79$ & 0,43 \\
\hline Financiamento * dummy para Mato Grosso & $-0,01^{* *}$ & $2,5 \mathrm{E}-03$ & $-2,14$ & 0,03 \\
\hline Investimento, em Reais & $4,0 \mathrm{E}-04^{* * *}$ & $1,3 \mathrm{E}-04$ & 3,14 & 0,00 \\
\hline Investimento * dummy para Mato Grosso & $-2,6 \mathrm{E}-04$ & 4,9E-04 & $-0,53$ & 0,60 \\
\hline Demografia, pessoas $/ \mathrm{km}^{2}$ & $-0,01$ & 0,01 & $-0,37$ & 0,71 \\
\hline Demografia * dummy para Mato Grosso & 0,39 & 2,46 & 0,16 & 0,88 \\
\hline № de cursos (Ciências Agrárias) & $-30,81$ & 32,23 & $-0,96$ & 0,34 \\
\hline Assentamento (dummy) & $-34,55$ & 42,51 & $-0,81$ & 0,42 \\
\hline Agências bancárias, em unidades & $-1,83^{* *}$ & 0,76 & $-2,40$ & 0,02 \\
\hline Permanentes (dummy) & $-201,07^{* * *}$ & 75,06 & $-2,68$ & 0,01 \\
\hline Temporária (dummy) & $-122,42^{*}$ & 69,23 & $-1,77$ & 0,08 \\
\hline Pastagem natural (dummy) & $-209,94^{* * *}$ & 70,38 & $-2,98$ & 0,00 \\
\hline Pastagem plantada (dummy) & $-148,34^{* *}$ & 65,07 & $-2,28$ & 0,02 \\
\hline Matas plantadas (dummy) & $-456,44^{* * *}$ & 166,24 & $-2,75$ & 0,01 \\
\hline Inaproveitável (dummy) & $-287,48^{* * *}$ & 82,53 & $-3,48$ & 0,00 \\
\hline Outliers & $655,35^{* * *}$ & 67,96 & 9,64 & 0,00 \\
\hline Fronteira.SP & 3,01 & 53,48 & 0,06 & 0,96 \\
\hline Fronteira.MT & 51,21 & 124,85 & 0,41 & 0,68 \\
\hline W* (Proporção) & $-28,74^{* *}$ & 11,95 & $-2,4052$ & 0,02 \\
\hline W* (Adubação) & $1,8 \mathrm{E}-04$ & 3,3E-04 & 0,5272 & 0,60 \\
\hline $\mathrm{W}^{*}($ Abubação * dummy para MT) & $1,3 \mathrm{E}-03$ & $1,0 \mathrm{E}-03$ & 1,2916 & 0,20 \\
\hline W* (Área média) & $3,13^{* * *}$ & 0,90 & 3,4851 & 0,00 \\
\hline$W^{*}(\text { Área média })^{2}$ & $-8,5 \mathrm{E}-04$ & $5,3 \mathrm{E}-04$ & $-1,6145$ & 0,11 \\
\hline $\mathrm{W}^{*}($ Área média * dummy para MT) & $-2,65^{* * *}$ & 0,91 & $-2,8998$ & 0,00 \\
\hline $\mathrm{W}^{*}\left((\text { Área média })^{2 *}\right.$ dummy para MT)) & $8,0 \mathrm{E}-04$ & $5,4 \mathrm{E}-04$ & 1,4792 & 0,14 \\
\hline $\mathrm{W}^{*}$ (Trator) & $-184,33^{* * *}$ & 54,82 & $-3,3622$ & 0,00 \\
\hline$W^{*}$ (Financiamento) & $-5,4 \mathrm{E}-05$ & $1,6 \mathrm{E}-04$ & $-0,3322$ & 0,74 \\
\hline $\mathrm{W}^{*}($ Financiamento $*$ dummy para MT) & $0,01^{* *}$ & 0,01 & 2,1416 & 0,03 \\
\hline $\mathrm{W}^{*}$ (Investimento) & $-2,6 \mathrm{E}-05$ & $3,8 \mathrm{E}-04$ & $-0,0692$ & 0,94 \\
\hline $\mathrm{W} *($ Investimento * dummy para MT) & $-8,2 \mathrm{E}-04$ & $1,3 \mathrm{E}-03$ & $-0,6522$ & 0,51 \\
\hline
\end{tabular}

Fonte: Resultados da pesquisa. 
308 Determinantes do custo de oportunidade dos fazendeiros em manterem a reserva legal - os casos paulista e mato-grossense

Tabela B1. Continuação...

\begin{tabular}{|c|c|c|c|c|}
\hline Variável & Estimativa & Desvio Padrão & Estatística $\mathbf{t}$ & P valor \\
\hline$W^{*}$ (Demografia) & $-0,25^{* * *}$ & 0,03 & $-7,5272$ & 0,00 \\
\hline $\mathrm{W}^{*}($ Demografia $*$ dummy para MT) & $-6,30$ & 7,80 & $-0,807$ & 0,42 \\
\hline $\mathrm{W}^{*}$ (№ de cursos) & $-37,81$ & 79,52 & $-0,4755$ & 0,63 \\
\hline $\mathrm{W}^{*}($ Assentamento $($ dummy $))$ & 6,59 & 74,68 & 0,0882 & 0,93 \\
\hline W* (Agências bancárias) & 1,41 & 2,35 & 0,6025 & 0,55 \\
\hline $\mathrm{W}^{*}($ Permanentes $($ dummy $))$ & $-84,42$ & 173,74 & $-0,4859$ & 0,63 \\
\hline $\mathrm{W}^{*}$ (Temporária $($ dummy)) & $-134,09$ & 155,66 & $-0,8614$ & 0,39 \\
\hline $\mathrm{W}^{*}($ Pastagem natural (dummy)) & $-98,57$ & 159,94 & $-0,6162$ & 0,54 \\
\hline $\mathrm{W} *($ Pastagem plantada (dummy)) & $-63,98$ & 147,20 & $-0,4346$ & 0,66 \\
\hline $\mathrm{W}^{*}$ (Matas plantadas $($ dummy $\left.)\right)$ & 156,40 & 418,92 & 0,3733 & 0,71 \\
\hline W* (Inaproveitável (dummy)) & $-117,50$ & 166,47 & $-0,7058$ & 0,48 \\
\hline$W^{*}$ (Outliers) & $-325,71^{* * *}$ & 108,24 & $-3,0091$ & 0,00 \\
\hline $\mathrm{W}^{*}$ (Fronteira.SP) & $-133,46$ & 90,08 & $-1,4816$ & 0,14 \\
\hline $\mathrm{W}^{*}$ (Fronteira.MT) & 24,32 & 305,28 & 0,0796 & 0,94 \\
\hline
\end{tabular}

Fonte: Resultados da pesquisa. 